\title{
Automated Result Process System Processing System (A Case Study of University of Port Harcourt)
}

\author{
Article by Iweriebor Elvis Erere \\ MSc Information Technology, Nigeria \\ E-mail: iweries@yahoo.com
}

\begin{abstract}
Due to enormous problems associated with manual computation of students' result and transcript processing in university of Port Harcourt, there is need for efficient method with error free that will enable result to be processed automatically. This system will accept multiple inputs and aid course advisers carry out their responsibilities effectively. A result is an official report and record of student courses with grades. Students result is critical to their graduation.

Currently, there is no reliable way to track incoming results. This creates problems for students and staff. Lost or misplaced result has unwanted consequences and delay graduation.

In this work, a computer software application was developed to facilitate the automated processing of the results. The software was developed in Java programming language in the form of a database, employing PostgreSQL Relational Database Management System. The developed software performed well and produced expected results on completion. With it, it was possible to compute Grade Point Average and Cumulative Grade Point Average for each student based on examination scores entered being the core idea behind the design.
\end{abstract}

Keywords: Relational, Database, Management, GPA, Software, Hardware, Programming, Java, Computer, Design, Examination, Record, PostgreSQL.

\section{Introduction}

Over the years several efforts has been made to alleviate the burden of result processing and transcript generation on the desk officers who are in charge of the five faculties in University of Port Harcourt at the Examinations and Records office.

The effort expended in the process of registration of students and computation of their examination results is awesome. Quite worrisome is the fact that these processes are carried out every academic session, putting the operators in a continuous and ever demanding cycle. The computation of examination results and registration of students is obviously an object-centered activity, the student being the dominant object in this case. Hence, the need to evolve a computerized process that will effectively and efficiently capture all the important data associated with the registration and examination result processing within the University and the interactions among the objects.

Students' Examination Result is the summary of each of the semester or four years performance in a degree program for Bachelor degree to be terminable. A students' Result is also demanded by a student who has finished Bachelors and Masters degree and wishes to transfer to another school or student who wishes to get a job.

Transcript is not given directly to a student. It is sent to the school that the student wishes to be transferred, or to the organization or establishment that requires the result.

A students' Result is prepared or formed by the scores entered on the designed score sheet by the individual subject lecturers on semester examinations. This genuine and noble desire necessitated the design and development of this project.

\section{Background of the study}

Founded in 1975, University of Port Harcourt (UNIPORT) is a second -generation Federal University Located in the Niger-Delta region of Nigeria with over 50,000 students and a strong focus in Petroleum Engineering. Formerly known as University College Port Harcourt, It has been ranked amongst the top ten universities in Africa and as the first in Nigeria by Times Higher Education 
(THE); a UK-based source for higher education information.

The vision of University of Port Harcourt is to rescue some of our wandering and teaming youths from further slide into academic and moral decay, and development and transformation of our society through sound and adulterated education. Its mission is to discover, sanctify and apply the knowledge of science, environmental and engineering for human well-being and sound development of man for better society.

The University's goal is to give efficacy to the University's motto and to its philosophy of education. The school embraces not only sound education for professional skills and competency in various fields; but also maintain strict discipline. We train the mind, body, soul and spirit in the exercise of obedience and self-control. The students must not only be intellectually and professionally prepared for different tasks and roles in the world, they must also be morally equipped to face the world itself with all its tensions, conflicts, challenges and contradictions. We achieve this with the help of God Almighty who is with us always.

The philosophy is to promote sound education for professional skills and competencies in various fields with strict discipline. By discipline the University meant the training of the mind, body and soul and spirit to obedience and self-control. Also to prepare the students to be intellectually and professionally sound for different tasks and roles in the word with its tensions, conflicts, challenges and contradictions.

In the University, there has been need for automated method of keeping data using computer and the right Software. The only method available to the school presently is the use of different forms of spreadsheet applications to collate and process academic results which also are still evident in other Nigeria universities. This method could not meet their demand for result generation, automated course registration and result storage in school database to also facilitate students' transcripts.

This problem used to delay the results of graduating or graduated students that have made some of them not to go for the National Youth Service Corp (NYSC) when they ought to or ought to have gone. It has even made some not to have gone at all. To solve this problem, there is a need to develop software that is accurate, error free as the problem has imposed so much stress on both exams and record and the management in Universities.

The University of Port Harcourt is made up of six (6) faculties namely:

1. Engineering with the following departments: Computer, Mechanical, Civil, Petroleum, Gas, Chemical and Electrical and Electronics Engineering.

2. Environmental with the following departments: Architecture, Urban \& Regional Planning and Estate Management.

3. Management and Social Sciences with the following departments: Accountancy, Economics, Business Administration, Public Administration, Political Science, Industrial Relation and Personnel Management, Mass Communication, Marketing, Banking and Finance.

4. Natural Sciences with the following departments: Biochemistry, Computer Science \& Information Technology, Industrial Chemistry, Mathematics \& Statistics and Microbiology \& Biotechnology.

5. Medicine and Health Science: Nursing, Laboratory Science, Medicine, Anatomy.

6. Agricultural Science: Crop Production, Botany, Fisheries and Animal Husbandry.

Table 1.0. University of port harcourt faculties and associated number of departments

\begin{tabular}{|l|l|l|}
\hline S/No & Faculty & Number of departments \\
\hline 1 & Engineering & 8 \\
\hline 2 & Management Sciences & 10 \\
\hline 3 & Natural Sciences & 7 \\
\hline 4 & Agricultural Science & 4 \\
\hline 5 & Medicine and Health Science & 5 \\
\hline 6 & Environmental & 4 \\
\hline$*$ & TOTAL & 38 \\
\hline
\end{tabular}




\section{University of port harcourt grading system}

In University Port Harcourt, the grade is by letters, A, B, C, D, E, and F. where A stands for 5.0, B $=4.0, \mathrm{C}=3.0, \mathrm{D}=2.0, \mathrm{E}=1.0$ and $\mathrm{F}=0.0$ i.e. anything below 1.0 which $\mathrm{E}$ (pass) is $\mathrm{F}$ (fail).

Below are the illustrations:

Table1.1. University of port harcourt grading system.

\begin{tabular}{|l|l|}
\hline Grade & Grade point \\
\hline A & $\mathbf{5 . 0}$ \\
\hline B & $\mathbf{4 . 0}$ \\
\hline C & $\mathbf{3 . 0}$ \\
\hline D & $\mathbf{2 . 0}$ \\
\hline E & $\mathbf{1 . 0}$ \\
\hline F & $\mathbf{0 . 0}$ \\
\hline
\end{tabular}

Table1.2. University of port harcourt degree classification

\begin{tabular}{|l|l|}
\hline CGPA & Class of degree \\
\hline $4.50-5.00$ & First Class \\
\hline $3.50-4.49$ & Second Class (Upper Division) \\
\hline $2.40-3.49$ & Second Class (Lower Division) \\
\hline $1.50-3.2 .39$ & Third Class \\
\hline Less than 1.5 & Fail \\
\hline
\end{tabular}

\section{Definition}

Automated Result Processing System (ARPS) is a set of software programs that is designed to control the institution's (practically using University of Port Harcourt ) storage, management, and retrieval of data (Result) in a database. Automated Result Processing System is categorized according to their data structures or types. It accepts requests for data from an application program and instructs the operating system to transfer the appropriate data. The queries and responses must be submitted and received according to a format that conforms to one or more applicable protocols. When an ARPS is used, information systems can be changed much more easily as the organization's information requirements change. Use of manual imputation of result is discarded and new categories of data can be added to the database so easily without disruption to the existing system.

A database management system in it provides the ability for many different users to share data and process resources. But as there can be many different users, there are many different database needs. The question now is: How can a single, unified database meet the differing requirement of so many users?

As this study entails adding a different form of database management in connection with organizational result computation and assessment. This brings about the use of Automated Result Processing system (ARPS).

Prior to this approach, the institution relied on the manual method of data processing and storage and each file used are with a specific application. Needless to say, file processing was bulky, costly and nonflexible when it came to supplying needed data accurately and promptly.

This study therefore, examines clearly the effect of the Design and Development of Result Processing System towards the improvement of University of Port Harcourt.

\section{Significance of the study}

The significance of this study is to examine closely the advantage of automated result processing system to the benefit of the University and the entire community.

The project work will help in a good number of ways to ease the delay in manual examination result processing. The software developed will help schools management to achieve efficient 
DOI: 10.21522/TIJAR.2014.04.02.Art009

ISSN: $2520-3088$

information management system. There are many other advantages, and some of them are listed below:

1. It saves time during examination processing

2. Database for course registration and examination result is maintained

3. References are very fast and delays can be avoided.

4. It allows easy access to stored information.

5. Help in reducing the costs such as labor, inventory and stationary.

6. To enhance speedy of the results.

7. To eliminate error due to manual processing.

8. To provide security measure to check student mischievous act of changing marks on the result sheet.

9. It will serve as a reference material to those who use this project material.

10. It is a contribution to knowledge.

11. It will provide information to other researchers/developers on how best and beneficial the use of a management information system can be in providing accurate information for an organization's decision making.

12. It will ensure high level quality service development of the management which will ensure that students are not subjected to undue suffering in collection of their transcript or clearance prior to the deployment for youth service

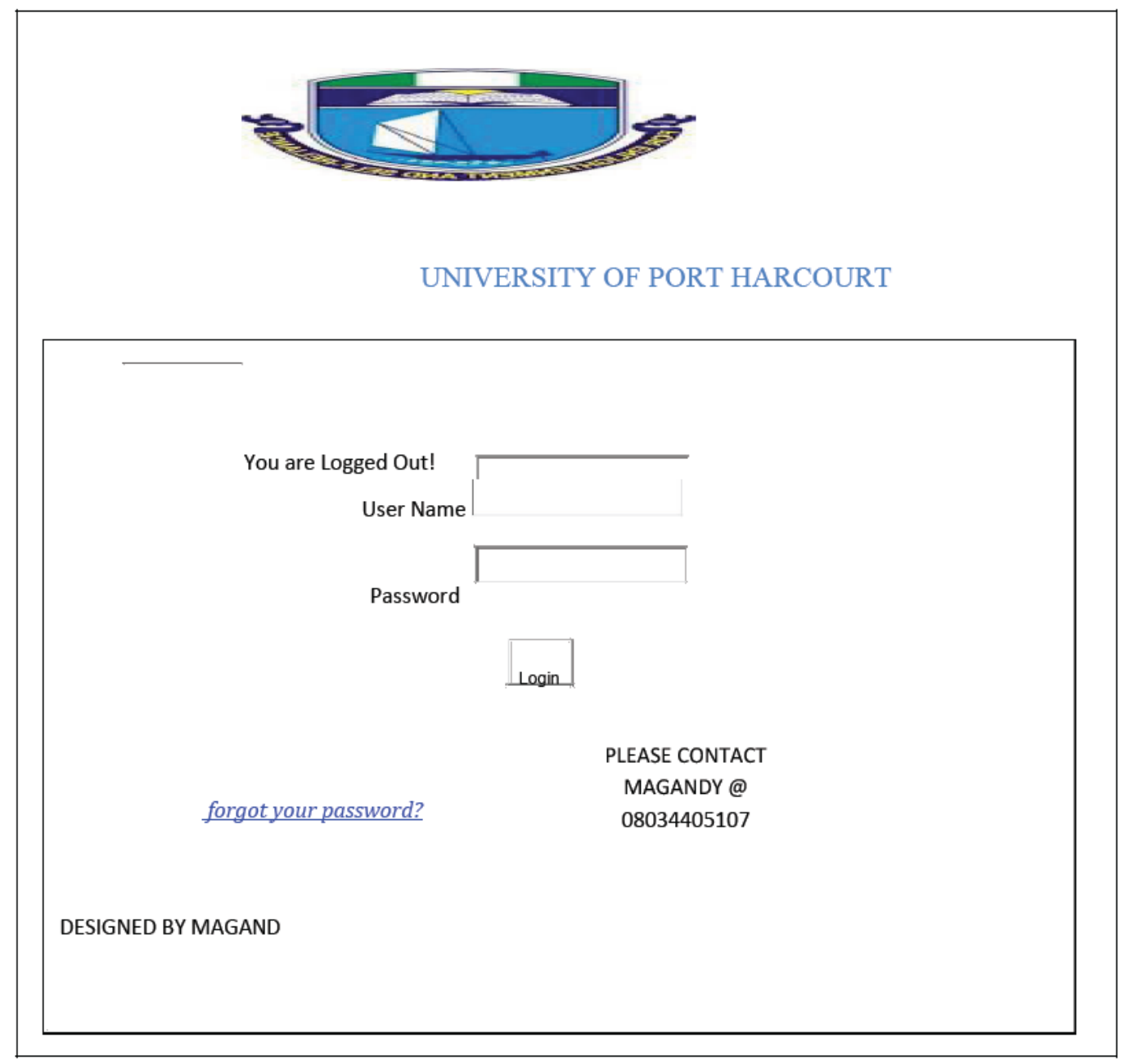

Figure 2.1. The administrative panel

\section{Summary}

The Automated Result Processing Systems is very important machine in the university environment and it performs all the activities of a result management system by providing the basic 
storage and retrieval technology. The result application software sends data to and receives data from the DBMS and you hardly noticed its activities. Yet great claims are made for different types of database and their particular offerings. You should at least be able to understand the basics to understand what you might be getting - or missing when you choose a Result Management System (RMS).

The result application stored in the database is so important because of its reliability, efficiency and flexibility which is capable to respond to the up-coming changes in the computer and information handling world and is commercially viable.

\section{Recommendation}

I recommend this work to the management of University of Port Harcourt to ease them the stress of manual system of result computation and storing of students information's. This will lead to the growth of the university.

I also recommend this work to all institutions that process the results of students.

\section{Conclusion}

The benefits of using the Automated Result Processing system cannot be over emphasized. This is because the system will increase the speed of processing results, increase accuracy in result computation, eliminate cases of misplacing files of students and reduce the pilling up of papers in the offices.

\section{References}

[1]. Afolabi, M. (1991). Education and Training Archives and Records Managers in Africa. Ibadan: Odun Publishing Company.

[2]. https://www.academia.edu/10427266/Student_Examination_Result_Processing_System

[3]. Baje, E. N. (1998). Records Management Program. Ibadan: Adeyomi Printing Press.

[4]. Brian, T. F. (2006). Database Design and Management ( $3^{r d}$ ed.). New York: Practice Hall Publishers pg 30-31.

[5]. Craig, S. M. (2002). Database Administration. Addison: Wesley Professional ISBN: 01741296.

[6]. Codd, E. F. (1970). A Relational Model for Large Shared Data Banks. In Communications Of the Data Banks.

[7]. Date, C. J. (2003). An Introduction to Database System ( $5^{\text {th }}$ ed.). Addison: Wesley ISBN 0-201-51381-1.

[8]. Delisle, M. (2009). Mastering phpMyAdmin 3.1 for Effective MySQL Management (4 ${ }^{\text {th }}$ ed.). New York: Packet Publishing.

[9]. Enwere, J. C. (1992). Records Management in Nigeria. Nigeria Librar and Information Service Review Lagos: Akin Publishing Ltd.

[10]. French, C. S. (1996). Computer Science. TJ International, UK.

[11]. Iwhiwhu, E. B. (2005). Management of Records in Nigerian Universities. Problems and prospects. The Electronic Library 23(30).

[12]. Mcdonald, I. (1995). Managing Records in the Modern Office. Training the Wild Frontier. Archivaria 39 (spring).

[13]. Nkiro, S. N. (2007). Principles of Database Management. Agbowo: Odun prints and pack.

[14]. Nwankwo, J. I. (1982). Establishment of Management Information. Insind Province, UNESCO Technical Report: Project PAK/77/038.

[15]. Popoola, S. O. (2000). Records Management Program in Nigeria: A Survey of Osun state Civil Service. Nigerian Libraries, 34(1).

[16]. Spencer, M. (2007). Database Application and Management. Lagos, Printice Printing Press Publishers.

[17]. Uwaifo, E. O. (199). The Features of RECORDS Management in Nigeria. The Nigerian Archivist. Journal of the Society of Nigeria Archivist. (2 \& 3), January and July.

[18]. Adinola, T. K. (2005). Coping With the Challenges of Database. Retrieved from http://databaseentry.org/history. 2008-02-10.

[19]. "History of PHP and Related Projects". The PHP Group. Retrieved from http://www.php.net/history. 2008-02-25. 
DOI: $10.21522 /$ TIJAR.2014.04.02.Art009

ISSN: $2520-3088$

[20]. Kenny, S.M. Database Backup and Recovery Basics. Retrieved from http://www.download.oracle.com. 2008-02-12. 